\title{
Correction to: Trade-offs Between Ecosystem Services and Opportunity Costs in Maintaining the Tonle Sap Lake Agro-ecosystem (Cambodia)
}

Malyne Neang, Philippe Méral, Olivier Aznar, and Christophe Déprés

Correction to:

Chapter 6 in: M. A. Stewart, P. A. Coclanis (eds.), Water and Power, Advances in Global Change Research 64, https://doi.org/10.1007/978-3-319-90400-9_6

This book was inadvertently published with an incorrect figure (Fig. 6.1 in page 92). The current version of the book is published with correct figure.

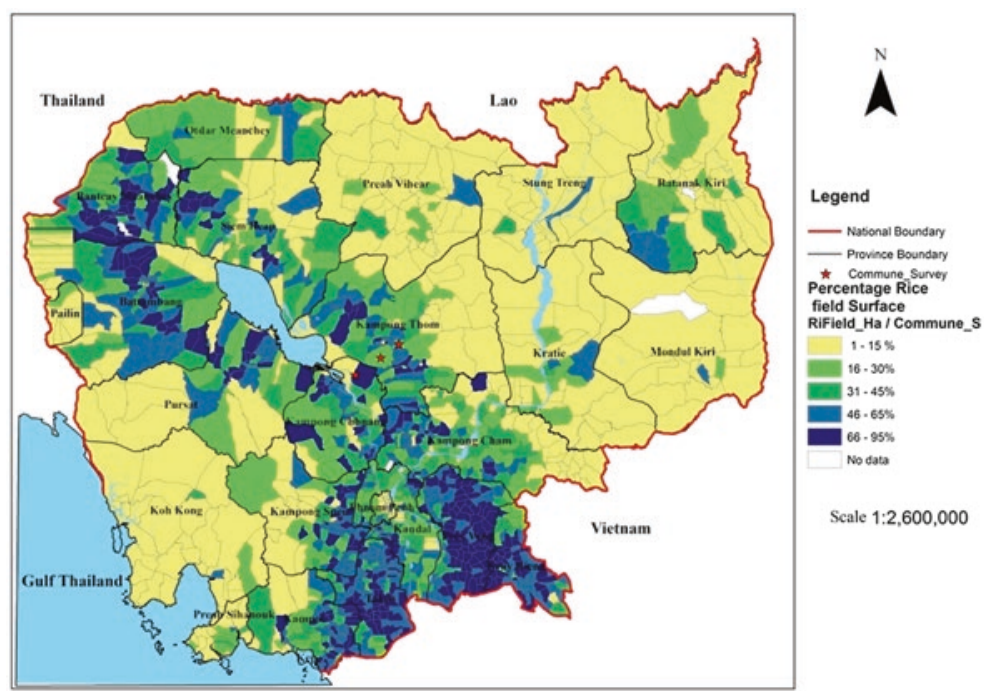

Fig. 6.1 Rice fields in Cambodia. (Source: Open Development Cambodia)

The updated version of this chapter can be found at https://doi.org/10.1007/978-3-319-90400-9_6 